[The fee for these degrees, except at "general admissions," is ten guineas for students not admitted as " advanced students."] Advanced students shall pay to the University Chest the same capitation tax as other members of the University, and under the same conditions as to standing (Graces June I, I893, and February 14, 1895): provided that the quarterly payment to be made by an advanced student, who has obtained a certificate of research but has not been admitted to a degree, and who has ceased to reside in the University, shall from and after the end of the eighth quarter from the commencement of residence be four shillings and threepence.

[The "capitation tax" referred to is thus in general ten shillings a quarter during the two years of residence, and four shillings and threepence a quarter thereafter until the advanced student removes his name from the boards of his College.]

The outcome of these regulations is this, that a graduate of a British, American, or other University, who can show evidence of special qualifications for advanced study in literature, law, history, or other like subject, or for scientific research, may be admitted under exceptionally favourable conditions to the University of Cambridge, He will not be required to pass the "previous examination " in Greek, Latin, elementary mathematics, and other subjects of preliminary education. He may reside two years instead of the three required of ordinary undergraduates. He will probably be allowed special privileges in respect of the University library, the museums, and the laboratories. He may become a candidate in the parts of certain of the Triposes concerned with his particular subject, or he may engage from the outset in independent research. If he approves himself sufficiently in the Tripos examination, or achieves results in relation to his research which may fairly claim "distinction," he may proceed to the degree of B.A. without further examination. Thereafter he need not reside further, but after the ordinary period of probation, pass to the higher degree of M.A. This opens the way to the doctorate in science or in letters for those whose after-work is of sufficient merit. A point of importance is contained in the second clause of Regulation 16 , which provides that work published elsewhere may be taken into account in deciding whether an advanced student is qualified for his certificate or degree.

The "Degree Committee" of a Special Board consists of the professors and other elected members of the Board, but not the examiners for Triposes, \&c., who are appointed for a year at a time. The special Boards deal respectively with theology, law, medicine, classics, oriental studies, mediæval and modern languages, mathematics, physics and chemistry, biology and geology, history and archæology, moral science, and music. The Triposes are the mathematical, classical, moral sciences, natural sciences, mechanical sciences, theological; law, historical, oriental languages, and mediæval and modern languages. It has yet to be determined what parts of these shall be specially opened to advanced students, but as most of them are divided into two parts, it is likely that the second or more advanced and specialised parts will as a rule be made available. The University has made concessions as to the fees to be paid by advanced students, and there is no doubt that as the scheme comes into working order, the colleges will follow the lead of the University in this respect.

The scheme is one which should lead to important developments in the future. Graduates of other universities, unless they came from Oxford or Dublin, or were specially "affiliated," could share in the advantages which Cambridge has to offer, only on condition of becoming mere undergraduate students, and so beginning their academic course over again. Now, if they are sufficiently qualified by previous study and attainments, they are admissible on a higher and definitely recognised footing, and may at once, enter on post-graduate work. It is to be hoped that, at least in English-speaking NO. I 343 , VOL. 52$]$ countries, the opportunities thus offered for higher study in Cambridge may soon be appreciated; and that a steadily increasing number of those who now from our colonies and the United States proceed to continentai universities in pursuit of learning may find in one of the old English universities a more natural and a more interesting academic resort.

\section{THE HEALTH OF LONDON.}

THE immense strides which have been marle in sanitary science, the well-nigh feverish eagerness with which all questions relating to health are pursued, causes the layman to turn with interest and, indeed, curiosity to any reliable record he can obtain of statistics relating to the public health.

"What," he asks, "is the actual practical result of all these efforts on the part of municipal authorities and other responsible public bodies on the health of our great cities?"

It is thus that statistics become invested with an interest even to the uninitiated, and there is no more striking tendency in the hygienic crusade which prevails than the sense of individual responsibility which it has succeeded in arousing in the conduct of sanitary matters, and the participation of the people themselves in measures of sanitary reform. Hence the compilation and issue by the London County Council of periodic reports on a variety of hygienic subjects ; and the appearance of "County Council Orange Books" may now be regarded as a familiar feature in the administration of that democratic body.

One of the most recent of these is the annual report of the London County Council's Medical Officer of Health for the year 1893 .

This weighty document bristles with figures, and embraces a variety of subjects, but to only a few of the more important of these can we briefly refer here.

Perhaps the most appropriate point to start from, is the consideration of some interesting data dealing with the expectation of life, actuarily calculated, enjoyed by Londoners from five years upwards in the period of $\mathrm{I} 88 \mathrm{I}-90$ and $\mathrm{I} 86 \mathrm{I}-70$ respectively.

These statistics go to show that the expectation of life of males at five years of age has improved from 47.49 years to 50.77 ; or, in other words, during the last period there has been a gain of $3 \cdot 28$ years. As regards females, we find the expectation of life has risen from 50.87 to 54.43 , or a gain of 3.55 years. At subsequent ages there is also, in all cases, an improvement, though relatively less than at age five, showing that the greater part of the gain is in the periods of youth and early maturity.

If we compare these tables with those of a similar nature, which have been compiled for each sex in Manchester and Glasgow from $188 \mathrm{I}-90$, we find that the expectation of life in London exceeds that enjoyed by the inhabitants of both these large cities.

Londoners may also congratulate themselves upon the fact that the death-rate in London was lower than that of the majority of the capitals of Europe and of $\mathrm{New}$ York; thus, we can contrast a death-rate of $2 \mathrm{I}^{\circ} 3$ per 1000 , with 21.8 in Paris, 22.3 in Rome, $24^{\circ} \mathrm{O}$ in Vienna, and $30^{\circ} 6$ in St. Petersburg, and in New York $23^{\circ} 9$ per I000.

As compared with our five largest cities--Manchester, Liverpool, Birmingham, Leeds, and Sheffield-London again can boast of the lowest death-rate; whilst our infant mortality, compared with that of other English towns having more than 200,000 inhabitants, was also lower in every case with the single exception of Bristol.

If we look more closely into the particulars of the death-rate, we find that, as regards the principal zymotic 
diseases, London shows an increased mortality over the average for the preceding ten years, the rate having risen from $2 \cdot 10$ to $2 \cdot 28$ per IOJ0; and although this zymotic death-rate compares favourably with that of the largest of our towns, yet as regards foreign capitals it is only exceeded in two cases, i.e. by that of Stockholm and Vienna.

This increase is largely due to the alarming rise which has taken place in deaths from diphtheria, a rise represented by a death-rate of 0.12 per 1000 in the years $1871-80,0^{\circ} 26$ in $1881-90,0^{\circ} 31$ in I89I, $0^{\circ} 44$ in 1892 , and, lastly, 074 in 1893 . Such a diphtheria death-rate is markedly in excess of that of other large English towns having a population of more than 200,000 , being, in fact, more than double that of any with the exception of West Ham (virtually a part of London); it was even ten times as great as the diphtheria death-rate of Nottingham, and six times as great as that of Liverpool.

Small-pox also appears to be on the increase, and influenza and pneumonia claimed a number of victims greatly in excess of the average of the preceding ten years ; and there is, also, a substantial increase registered in the scarlet-fever death-rate.

But the most serious problem which we have to face is our diphtheria epidemic; various attempts have been made to ascertain to what it can be traced, but so far, it must be confessed, we are without any satisfactory clue as to its source. It has been attributed by some to alterations in the classification of diseases, more especially by transference to diphtheria of deaths which in former years were registered as croup, by others to increased facilities for the spread of infection afforded by increased school attendance, to sewer ventilators, \&c. ; but the fatal objection to all these explanations is that they are circumstances which are shared by all the other great cities and towns of the country, and yet London alone is pre-eminent in its death-rate from diphtheria.

There appears, however, to be a very decided tendency in England for diphtheria to increase in densely inhabited centres, whilst in the more sparsely populated districts there is a decrease, which has been especially emphasised of late years.

Curiously, this is not the experience of our neighbours in Germany. Dr. Hecker has quite recently conducted an elaborate inquiry into the diphtheria death-rate during the years $1883-93$ in a number of German cities, and he states that it is a decreasing one.

The problem of diphtheria in London is as yet unsolved, neither is its solution likely to be accomplished through such isolated, individual investigations such as have hitherto prevailed. What is required is the appointment of a Commission, composed of men abreast of the time, acquainted with modern methods, and capable of pursuing experimentally, if necessary, the course of this scourge.

Fortunately, as regards cholera, our past experience has enabled us to cope satisfactorily with what was at one time our most dreaded foe, and although Europe has suffered severely, England has escaped since the outbreak of cholera in London in the year 1866.

The freedom of London from this, to a large extent, water-borne disease brings us to the consideration of another malady in the communicability of which water is also largely responsible, i.e. typhoid fever.

In this connection it is satisfactory to read the following: "A point well deserving of observation, is the diminishing London typhoid fever death-rate."

Although it cannot be assumed that it is entirely due to improvement in the water supply of London, yet the evidence of the connection between typhoid fever and mpure water supplies, has been too firmly established not to permit of the London water companies obtaining some credit for this improved hygienic condition.
On this point, the evidence afforded by the city of Zürich is instructive, for it has been distinctly found that since the establishment of the new filtration works in 1886 , and the consequent greatly improved bacterial quality of the water distributed, a very marked diminution has taken place in the number of cases of typhoid fever. This fact has been vouched for after most careful investigation of facts and statistics by the city authorities.

Again, we have only to recall the invariable increase in cases of typhoid fever in Paris, when in consequence of an insufficient supply of purer sources of water, recourse has to be had to that of polluted river Seine water. Now Dr. Percy Frankland, in his reports to the Local Government Board, showed, for the first time in this country, the bacterial purification which Thames water undergoes at the hands of the London water companies; and although in his recent report to the Royal Society on the vitality of the typhoid bacillus in various waters, he points out that, whilst unable to increase in numbers, it can yet remain alive for days and weeks in water, yet we may assume that the typhoid bacillus will submit, as all ordinary water microbes, to the purification processes which Thames water undergoes before delivery, processes which Dr. Percy Frankland has repeatedly shown, removes frequently as many as 99 per cent. of the bacteria present.

Under the heading of "Administration," we read that the Council's inspectors made numerous inspections of dairies and milk-shops, as well as cow-sheds ; as a result of these investigations, no less than 133 cases of scarlet fever were discovered as occurring on milk-shop premises, 46 cases of diphtheria and membranous croup, 2 I cases of typhoid fever, Io cases of small-pox, 5 cases of erysipelas, and 2 cases of measles. These probably represent only a proportion of the actual number of cases which took place in such establishments. Knowing as we do that milk offers every facility for the growth and abundant multiplication of pathogenic germs, it may be easily conceived how much zymotic disease may have been disseminated broadcast from these centres of infection.

In the recent report issued by the Royal Commissioners on tuberculosis, we find the following significant paragraph: "In regard to milk, we are aware of the preference by English people for drinking cow's milk raw, a practice attended by danger on account of possible contamination by pathogenic organisms. The boiling of milk, even for a moment, would probably be sufficient to remove the very dangerous quality of tuberculous milk."

We quote these words in full, not only because of the official weight which attaches to them, but because it is of such great hygienic importance that these facts should be known and realised by the general public.

On the continent, the practice of drinking raw milk is fast becoming obsolete, and sterilised milk is an article of commerce, and successful so-called "milk sterilising associations" have been formed for its distribution.

We have seen that, as regards the zymotic-disease death-rate, London is less favourably situated than the majority of the capitals of Europe. May we not possibly find at least one cause of this, to us humiliating fact, in the insular prejudice which prevails in favour of raw milk?

In conclusion, valuable as statistics may be and undoubtedly are, it must be remembered that there is yet much which statistics cannot reveal, that a lower deathrate cannot express the whole result of hygienic enterprise and progress. To adequately measure the value of sanitary reform to the community at large, we must look as well to the numerous and important improvements which have resulted in the increased comfort and wellbeing of the individual, and it is in such directions that the London County Council has accomplished some of its most useful and meritorious work.

NO. I 343 , VOL. 52] 